\title{
Firma Değerinin Piyasa Çarpanları ile Tahmin Edilmesi: BIST Dokuma, Giyim Eşyası Ve Deri Sanayii Sektöründe Bir Uygulama* $^{*}$
}

\author{
Cengiz TORAMAN** \\ Mehmet KÖRPIं ${ }^{* * *}$
}

\section{ÖZET}

Firma değerini belirlemede farkl yöntemler bulunmakla birlikte, bu yöntemlerde temel amaç en doğru firma değerinin belirlenmesidir. Bu çalışmada firma de ̌̆erinin tahmininde tarihi verileri kullanan değerleme yöntemlerinden karşılaştırmalı değerleme yöntemi diğer adıyla piyasa çarpanları yöntemi incelenmiş, çalışma kapsamında yer alan uygulamada yöntemin firma değeri tespitindeki başarısını ortaya koymak amaçlanmıştır. Çalışmada BIST dokuma, giyim eşyası ve deri sanayii sektöründe 2003-2012 yillart arasında faaliyetlerini devam ettiren 20 firmaya ait veri seti kullanilarak, 03.05.2013 tarihinde halka arz olan ROYAL HALI' nın değer tahmini yapılmış ve piyasa çarpanları ile firma değeri tahminin başarısı tartışılmıştır.

Anahtar Kelimeler: Firma Değeri, Piyasa Çarpanları, BIST Dokuma Sanayii.

JEL Sinıflandırması: G11, G30, L67.

Firm Valuation Using Market Multipliers: Evidence from Apparel And Leather Industry in Istanbul Stock Exchange

\section{ABSTRACT}

There are different methods for determining the firm value. Although these methods vary, the main purpose here is to determine the true value of the firm. In this study, a comparative valuation method, that is also called market multipliers, is used for determining the value of corporations. We used data set of 20 firms operate in textile, clothing and leather industry in Istanbul Stock Exchange during the period 2003 and 2012. We estimated the value of ROYAL HALI Co. which was offered to public in March 2013 and discussed the robustness of model for corporate valuation.

Keywords: Firm Value, Market Factors, Istanbul Stock Exchange (BIST), Apparel and Leather Industry.

Jel Classification: G11, G30, L67.

\footnotetext{
* Bu çalışma "3rd International Symposium on Accounting and Finance ISAF 2014-Tokyo, Japan”da sunulmuştur

** Prof. Dr. Cengiz Toraman, Gaziantep Üniversitesi, İİBF İşletme Bölümü, cengiztoraman@gmail.com

*** Öğr. Gör. Mehmet Körpi, Gaziantep Üniversitesi, Naci Topçuoğlu MYO, mehmetkorpi@hotmail.com
} 


\section{GİRiş}

Değer, satışa sunulan mal veya hizmetlerin alıcı ve satıcı tarafından belirlenen temsili fiyatıdır (Chambers,2009:5). Değerleme, varlıkların değerinin belirlenmesinde gerçekleştirilen bütün faaliyetlerin parasal olarak ifadesidir. Firma değerlemesi ise firmanın belirli bir zamanda, belirli bir yerde, firmanın içinde bulunduğu her türlü koşulun ve özelliğinin dikkate alınarak bir değer verilmesidir (Oymak,2009:4). Firma değerlemesinin amacı, piyasada varlıkların değeri konusunda tam bilgiye sahip istekli alıcıların ve satıcıların, herhangi bir zorlama olmadan, söz konusu varlık için piyasada takdir ettikleri alım-satım değerinin tespitidir (Bradford, 1993:7).

Firmalarda temel amacın, 1900'lü yıllarda firma karının maksimum kılınması olarak ifade edilirken günümüzde firmanın net bugünkü değerini hissedarları açısından maksimum kılmak olarak tanımlanmaktadır (Üreten ve Ercan, 2000:1-2). Buna paralel olarak finans literatüründe değerleme konusu üst sıralarda yer almakta ve değerlemenin öneminin sürekli artması ile beraber hem finans akademisyenleri, hem de uygulayıcıları ihtiyaçlara cevap verebilmek için yeni yöntemler geliştirmektedir.

Anthony (1960), kar maksimizasyonunun bir firmanın asıl amacı olmadığını, performans ve kar üzerinde durulan noktaların tek basına bir anlam ifade etmeyeceğini vurgulamıştır. Firma amacının kar maksimizasyonu olduğu değil firmanın bugünkü değerini ortakları açısından maksimum kılmak olduğunu belirtmiştir (Ercan vd.2006:1).

Son zamanlarda, Türkiye dahil dünyanın her köşesinde halka açılma ve özelleştirmeler, şirket birleşmeleri ve devirleri, sermaye piyasalarının gelişmesi sonucunda borsada hisse senetlerine arz ve talebin büyük ölçüde artması ile her türden yatırımcı değerleme konusuna ihtiyaç duymaktadır. Gerçek firma değerinin doğru tahmin edilmesi, hisse senedi piyasasında varlıkların yönetiminden sorumlu kimseler için büyük öneme sahiptir.

\section{KARŞILAŞTIRMALI DEĞERLEME YÖNTEMI}

Karşılaştırmalı değerlemenin temelini, aynı özelliklere sahip karşılaştırılabilir firmalara ait veriler kullanılarak firma değerinin tespit edilmesi oluşturmaktadır. Karşılaştırmalı değerlemede değeri tespit edilmek istenen firmanın değeri, karşılaştırılabilir hisse senetlerinin değerleri dikkate alınarak, bazı değişkenlere bağlı olarak belirlenmektedir (Park ve Lee, 2003:332).

Bu yöntem, değerlemesi yapılacak firmanın şirket değeri ile aynı piyasada yer alan diğer firmaların şirket değerlerinin birbirleri için bir anlam ifade ettikleri varsayımına dayanmaktadır. Bu yöntemde aynı sektörde faaliyet gösteren diğer firmaların çeşitli rasyolarından hareketle bir şirket değeri hesaplanmaya çalışılır. Bu yöntemde önemli nokta 
doğru katsayı yönteminin ve karşılaştırılabilir firmaların doğru seçilmesidir (Üreten ve Ercan, 2000:122).

Uygulaması çok kolay olan ve borsa analistlerinin sıklıkla kullandığı bu yöntem yatırımcıların potansiyel pazar algılamasını yansıtır. Yöntemin nispeten az sayıda varsayım gerektirmesi, indirgenmiş nakit akışları yöntemine göre kısa sürede yapılabilmesi ve yöntemin kolay anlaşılabilir ve anlatılabilir olması yöntemin yaygın biçimde kullanılmasının nedenidir. $\mathrm{Bu}$ yöntemde karşılaştırılabilir şirket bulmaktaki güçlükler ve uluslararası benzer firmaların karşılaştırılmasında farklı ülkelerdeki değişik muhasebe uygulamaları gerçek piyasa değerini bulmayı zorlaştıran unsurlardır (PriceWaterhouseCoopers Türkiye Danışmanlık Hizmetleri, 2006:41).

Karşılaştırma yönteminde değerlemede aşamalar aşağıdaki gibi belirlenmektedir (Üreten ve Ercan, 2000:123-126):

Karşılaştırılabilir firmaların seçilmesi; analiz edilen firmanın fiyatını bulmak için diğer firmaların katsayıları kullanılacağı için analiz edeceğimiz firmaya benzer firmaları tespit edip değerlendirmede kullanmamız gerekir.

Kullanılacak oranların seçilmesi; teoride değerlendirmede hangi katsayıların kullanılması gerektiği konusunda aydınlatıcı bir bilgi bulunmamaktadır. "Piyasa çarpanları" olarak adlandırılan oranlardan en çok kullanılan beş çarpan: Fiyat/Kazanç(F/K) çarpanı, Piyasa Değeri/Defteri (PD/DD) Çarpanı, Fiyat/Nakit Akım (F/NA) çarpanı, Fiyat/Net Satış (F/S) çarpanı ve Firma Değeri/FAVÖK çarpanlarıdır.

Sektördeki benzer firmaların ortalamasının bulunmasl; değeri hesaplanacak firmanın benzeri olan firmalardan bir grup oluşturduktan sonra, kullanılacak her bir oran için ortalama hesaplanır.

Değerlendirilen firmanın performansının tahmin edilmesi; değerlemede kullanılacak kriterin büyüklügü tahmin edilerek bu tahmin karşılaştırılabilir firmaların ortalama katsayısına uygulanır.

Firmanın değerinin bulunması; son aşamada daha önce bulunan karşılaştırılabilir firmaların ortalama katsayısını, öngörülen firma performansına uygulanarak firmanın tahmini değerini tespit etmektir.

\subsection{Fiyat/Kazanç Oranı (F/K)}

$\mathrm{Bu}$ yöntemin hareket noktası, hisse başına net kar ile hisse senedi fiyatı arasında uygun bir çarpan katsayısı bulunmasıdır. Fiyat/Kazanç $(\mathrm{F} / \mathrm{K})$ oranı işletmenin her bir TL'lik hisse senedi başına düşen net karına karşılık, ilgili hisse senedi konusunda yatırımcıların ne kadar ödemeye razı olduklarını gösterir (Konuk,2006:53). Bu yöntemde firma değeri şöyle hesaplanır: 
F/K = Hisse Senedi Piyasa Fiyatı / Hisse Başına Net Kar

Firma Değeri $=$ Seçilen Sektör veya Piyasa Ortalama F/K * Firma Net Karı

\subsection{Piyasa Değeri/Defter Değeri Oranı (PD/DD)}

PD/DD oranı, hisse senedi piyasa değerinin hisse başına özkaynak değerine bölünmesi ile bulunmaktadır. Bu oran, bir şirketin piyasa değerinin özkaynaklarının kaç katı olduğunu gösterir. Bir şirketin özkaynağı, toplam varlıklarından borçlarının çıkarılmasıyla bulunur. $\mathrm{Bu}$ yöntemde, firmaların PD/DD oranın aynı sektörde bulunan firmalar için aynı olduğu varsayımından hareket edilerek firma değeri tespit edilmektedir (Oymak, 2009: 35). Bu yöntemde firma değeri şöyle hesaplanır:

PD/DD = Hisse Senedi Piyasa Fiyatı / Hisse Başına Düşen Defter Değeri

Firma Değeri $=$ Seçilen Sektörün veya Piyasanın Ortalama PD/DD Oranı * Şirketin Defter Değeri

\subsection{Fiyat/Nakit Akımı Oranı (F/NA)}

$\mathrm{F} / \mathrm{K}$ oranı yöntemine alternatif olarak oluşturulan F/NA yönteminde, piyasa değeri ile nakit akımları arasında ilişki kurularak, bu ilişki yardımıyla benzer firmaların değeri tahmin edilmektedir (Chambers, 2009:224). Şirketler arasındaki amortisman uygulamalarının faklı olmasından dolayı net kar yaklaşımı yerine, nakit akımı yaklaşımının uygulanması daha gerçekçi bir firma değeri tespiti sağlayacaktır (İvgen, 2003: 124). Hesaplamalarda nakit akımı olarak net kar ile amortisman toplamı alınmaktadır. Bu yöntemde firma değeri şöyle hesaplanır:

Fiyat/Nakit Akımı = Hisse Senedi Piyasa Fiyatı $/$ Hisse Senedi Başına Nakit Akımı(Net Kar + Amortisman)

Firma Değeri $=$ Seçilen Sektör veya Pazarın Ortalama F/NA Oranı * Şirket Nakit Akımı

\subsection{Fiyat/Satış Oranı (F/S)}

Fiyat/Satış oranı firmanın borsadaki değerinin iş hacminin kaç katı olduğunu gösterir. F/S katsayısı, aynı endüstride çalışan firmaların karşılaştııılmasında en çok kullanılan yöntemlerden biridir. $\mathrm{Bu}$ oranın temelinde yatan varsayım, bir endüstrideki brüt kar marjlarının ve işletme etkinliğinin genellikle benzer olduğudur (Üreten ve Ercan, 2000:133). $\mathrm{Bu}$ yöntemde firma değeri şöyle hesaplanır:

Fiyat / Satış Oranı $=$ Hisse Senedinin Cari Piyasa Değeri / Hisse Başına Satış Geliri

Firma Değeri $=$ Seçilen Sektör veya Pazarın Ortalama F/S Oranı * Şirket Hisse Başına Satış Geliri 


\subsection{Firma Değeri/Faiz Amortisman Vergi Öncesi Kar (FD/FAVÖK)}

Firmanın cari dönemdeki tüm borç ve alacaklarıyla beraber satın alınması durumunda ortaya çıkan değerdir ve aşağıdaki gibi hesaplanır (İvgen, 2003:132):

FD/FAVÖK = Özkaynakların Piyasa Değeri + Mali Borçların Piyasa Değeri (Mali Borçlar-Hazır Değerler) / FAVÖK

$\mathrm{Bu}$ rasyo işletmenin nakit akımlarını esas alan, ancak sermaye ihtiyacını içermediği için eleştirilen kullanışlı bir yöntemdir. FAVÖK işletmenin net karlılığının ve borç ödeme kapasitesinin bir göstergesidir. İşletmelerin karşılaştırılmasında faaliyet karı ile net kar rakamlarının kullanılması yanıltıcı olabileceğinden FAVÖK kullanılması analizlerde tavsiye edilmektedir.

\section{LITERATÜR}

Firma değerlemesi ilk olarak Berle ve Means'in 1932 yılında yaptıkları çalışmayla gündeme gelmiştir. Daha sonra 1976'da Jensen ve Meckling yaptıkları çalışmalarla bu konu üzerindeki tartışmaları sürdürmüşlerdir. Sonraki dönemlerde yapılan çalışmaların büyük bölümü firma değeri ve işletme performansı arasındaki ilişkiler üzerine yoğunlaşmıştır. İşletme performansının artması dolaylı olarak firma değerinin de artmasında etkili olmaktadır.

Asquith (1983) tarafindan yapılan çalışmaya göre, piyasa çarpanları ile değerleme ya da göreceli değerleme olarak da adlandırılan karşılaştırmalı değerleme yöntemi firma değerlemesine ilişkin analizlerde en çok kullanılan yöntemdir.

Tseng(1988), 1975-1985 yılları arasında NYSE ve AMEX'de işlem gören hisse senetlerini incelediği çalışma sonucunda piyasa değeri kontrol altına alınması durumunda $\mathrm{F} / \mathrm{K}$ oranının tek basına net etkisinin anlamlı olmadığını tespit etmiştir.

Cheng ve McNmara tarafindan yapılan Amerika Birleşik Devletlerindeki şirketlerin cari piyasa değerleri ile Fiyat/Kazanç (F/K) ve Fiyat/Defter Değeri(F/DD) oranları arasındaki ilişkiyi sorgulayan bir çalışmada şirket değerleri, F/K, F/DD ve F/K-F/DD kombinasyonu ilişkilendirilmiştir. Yapılan çalışmadan şirket değerlerini açıklayabilme açısından $\mathrm{F} / \mathrm{K}$ oranının F/DD oranına göre belirgin bir üstünlüğü olduğu ve F/K-F/DD oranlarının birlikte kullanılmasının şirket değerini daha iyi açıkladığı sonucuna varmışlardır.

Cooke, Omura ve Willett (2009), 5 Japon holdinge ait 1950-2004 dönemi verilerine ulaşarak üç muhasebe değişkenin piyasa değeri ile arasındaki ilişkileri vektör hata düzeltme modeliyle analiz etmişlerdir. Araştırma bulguları seçilen 5 firmanın 4'ünde varlıkların net defter değeri ile piyasa değerleri arasında uzun dönemli ilişki olduğu yönündedir. Söz konusu bulgu, değer ilişkisi analizinde hisse başına defter değeri değişkeninin piyasa değerinin açıklanmasında yeterli bir bilgi olduğu şeklinde yorumlanmıştır. 
Çınabal (2008), İMKB'de işlem gören taş ve toprağa dayalı sanayi dahilinde seçilen 16 adet firma verileri üzerinde yapılan çalışmada firma değerlemesinde şirketlerin \%50 sinde Fiyat / Kazanç oranı türetilen kanonik denklem içinde pozitif bir katkı sağlarken, geri kalan \%50 sinde ise negatif katkı sağlamıştır. Piyasa değeri/defter değeri ise şirketlerin \%94 ünde hem negatif hem de düşük katkısı olan değişken olmuştur.

Birgili ve Düzer (2010), finansal oranlar ile firma değeri arasında ilişkiyi İMKB100 'de yer alan 58 işletmeye ait 2001-2006 yılları arasındaki verileri kullanarak ampirik olarak araştırmıştır. Ampirik bulgular, piyasa çarpanları olan F/K, PD/DD oranlarının firma değeri ile pozitif anlamlı bir ilişkinin var olduğu saptanmıştır.

Hatipoğlu (2011), İMKB enerji sektöründe işlem gören 5 firma için uyguladığ 1 göreceli değerleme yönteminde $\mathrm{F} / \mathrm{K}$ ve $\mathrm{F} / \mathrm{S}$ oranı hiçbir firmada doğru tahminde bulunmamıştır. PD/DD 2 firmada doğru tahminde bulunurken, F/NA 1 firmada doğru tahminde bulunmuş, FD/FAVÖK sadece bir firmada doru tahminde bulunmuştur. Genel olarak değerlendirildiğinde indirgenmiş nakit akımları yöntemi bütün firmaların 2010 yılı borsa performanslarını tahmin etmede, göreceli değerleme yöntemlerine göre daha sağlıklı sonuçlar vermiştir.

Savsar (2012), İMKB 100 Endeksine dahil olan, Gıda-İçki-Tütün, Enerji ve Metal Ana Sanayii sektörlerindeki firmaların firma değeri ile Borsa Performans Oranları arasındaki ilişkiyi incelemek üzere yaptığı panel veri analizi sonucunda kurulan model istatistiki olarak anlamsız çıkmıştır. Yani borsa performans oranlarında ki değişim şirketin firma değerini etkilememektedir denilebilir.

\section{UYGULAMA}

\subsection{Veri Seti}

Çalışmada, hisse senetleri Borsa İstanbul'da (BIST) Dokuma, Giyim Eşyası Ve Deri Sanayii sektöründe işlem gören 2003-2012 yılları arasında faaliyeti süreklilik gösteren 20 firmanın verileri kullanılmıştır. İflas, birleşme nedeni ile verisine ulaşılamama veya herhangi bir nedenle BIST kotasyonundan çıkarılan firmalarda süreklilik kısıdını sağlayamadıklarından araştırma dışında bırakılmıştır.

Çalışmada, firmalara ilişkin veriler 2003-2008 yıllarına ait verileri Borsa İstanbul'un (BIST) resmi internet sitesinden, 2009-2012 yıllarına ait veriler ise Kamuyu Aydınlatma Platformu'nun (KAP)'in resmi internet sitesinden indirilen mali tablolardan elde edilmiştir. Çalışmaya dâhil edilen firmalar aşağıdaki tabloda gösterilmiştir: 
Tablo 1. BIST Dokuma, Giyim Eşyası ve Deri Sanayii Sektörü Firmaları

\begin{tabular}{cll}
\hline NO & KOD & ŞIRKET ADI \\
\hline \hline 1 & ALTIN & ALTIN YILDIZ \\
2 & ARSAN & ARSAN TEKSTİL \\
3 & ATEKS & AKIN TEKSTILL \\
4 & BISAS & BISAŞ TEKSTİL \\
5 & BOSSA & BOSSA \\
6 & BRMEN & BİRLIK MENSUCAT \\
7 & DERIM & DERIMOD \\
8 & DESA & DESA DERİ \\
9 & ESEMS & ESEM SPOR GIYİM \\
10 & GEDIZ & GEDİZ İPLİK \\
11 & IDAS & İDAŞ \\
12 & KORDS & KORDSA GLOBAL \\
13 & LUKSK & LÜKS KADİFE \\
14 & KRTEK & KARSU TEKSTİL \\
15 & MEMSA & MENSA \\
16 & MNDRS & MENDERES TEKSTİL \\
17 & SKTAS & SÖKTAŞ \\
18 & SNPAM & SÖNMEZ PAMUKLU \\
19 & YATAS & YATAŞ \\
20 & YUNSA & YÜNSA \\
& & \\
\hline
\end{tabular}

\subsection{Kullanılan Piyasa Çarpanları}

Piyasa çarpanları olarak en çok kullanılan beş çarpan: Fiyat/Kazanç(F/K) çarpanı, Piyasa Değeri/Defteri (PD/DD) Çarpanı, Fiyat/Nakit Akım (F/NA) çarpanı, Fiyat/Net Satış (F/S) çarpanı ve Firma Değeri/FAVÖK çarpanları seçilmiştir.

\subsection{Bulgular}

BIST Dokuma, Giyim Eşyası Ve Deri Sanayii sektöründe son 10 yıldır faaliyet gösteren firmalara ait mali tablo kalemleri kullanılarak hesaplanan F/K oranları aşağıdaki gibidir: 
Tablo 2. Dokuma, Giyim Eşyası Ve Deri Sanayii Sektörü Firmaları İçin F/K Oranları

\begin{tabular}{lrrrrrrrrrr}
\hline FİRMA & $\mathbf{2 0 0 3}$ & $\mathbf{2 0 0 4}$ & $\mathbf{2 0 0 5}$ & $\mathbf{2 0 0 6}$ & $\mathbf{2 0 0 7}$ & $\mathbf{2 0 0 8}$ & $\mathbf{2 0 0 9}$ & $\mathbf{2 0 1 0}$ & $\mathbf{2 0 1 1}$ & $\mathbf{2 0 1 2}$ \\
\hline \hline ALTIN & - & 71,05 & 4,94 & - & 27,15 & - & 5,65 & 5,64 & 30,54 & - \\
ARSAN & - & - & - & - & - & - & - & - & 11,13 & 16,26 \\
ATEKS & 20,79 & 7,41 & 1154,08 & - & - & - & - & - & 232,26 & 22,11 \\
BISAS & - & - & - & - & - & 3,18 & - & - & - & - \\
BOSSA & 27,02 & 4,62 & 21,76 & 7,10 & 8,36 & 8,72 & - & 54,38 & 5,21 & 8,05 \\
BRMEN & 27,73 & 14,29 & - & - & 26,94 & - & - & - & - & - \\
DERIM & 51,01 & - & 10,34 & 6,63 & 8,98 & 39,69 & - & 17,48 & 11,29 & 12,69 \\
DESA & - & 5,65 & 11,42 & 14,77 & 8,95 & - & - & 93,46 & 36,20 & 14,27 \\
ESEMS & - & - & - & - & 9,13 & - & - & 0,75 & 0,31 & 9,43 \\
GEDIZ & - & - & - & - & - & - & - & 5,70 & 1469,39 & - \\
IDAS & 5,05 & 5,83 & - & 230,96 & - & - & 3,19 & - & - & - \\
KORDS & 9,81 & 9,52 & 12,35 & 13,54 & 29,86 & 6,12 & 12,08 & 16,23 & 7,81 & 17,71 \\
LUKSK & 17,70 & 6,76 & 11,64 & 21,46 & - & - & - & 198,02 & 13,73 & 13,80 \\
KRTEK & - & - & - & 26,72 & 10,84 & - & 25,79 & 56,83 & 19,06 & - \\
MEMSA & 4,12 & - & - & - & - & - & - & 21,14 & - & - \\
MNDRS & 17,74 & 14,75 & 17,80 & 7,16 & - & - & 5,11 & 5,78 & 4,64 & - \\
SKTAS & 3,62 & 4,87 & 31,46 & 14,91 & 6,95 & 4,34 & 17,71 & 9,87 & 9,17 & - \\
SNPAM & - & - & 86,24 & - & 26,90 & - & 15,46 & - & 49,55 & 64,85 \\
YATAS & - & 45,58 & - & 11,56 & 9,08 & - & 61,11 & 60,31 & 10,44 & - \\
YUNSA & 16,84 & 7,43 & 9,40 & 5,52 & 18,96 & - & - & 11,62 & 7,68 & 20,81 \\
\hline Ortanca & 17,70 & 7,42 & 12,35 & 13,54 & 9,98 & 6,12 & 13,77 & 16,85 & 11,21 & 15,27 \\
\hline Genel Ortanca & & & & & & $\mathbf{1 2 , 5 2}$ & & & & \\
\hline \hline & & & & & & & & & &
\end{tabular}

Yapılan hesaplamalar sonucunda, Dokuma, Giyim Eşyası Ve Deri Sanayii sektöründe son 10 yıldır faaliyet gösteren şirketler için $\mathrm{F} / \mathrm{K}$ oranlara ulaşılmıştır. Her bir yılın ortalaması ve genel ortalama alınırken aşırı uç değerler olduğundan ortanca (medyan) yöntemi kullanılmıştır. Sonuçta ilgili sektör için ortalama F/K 12,52 çıkmıştır.

Değerlemesi yapılacak olan ROYAL HALI firmasının 2012 y1l sonu kazancı 41.940.000 TL, borsada işlem gören hisse senedi sayısı ise 60.000 .000 adettir. Firmanın hisse başına kazancı 0,70 TL'dir.

ROYAL HALI firmasının hisse başı değeri = Sektör Ortalama F/K * Firmanın HBK

ROYAL HALI firmasının hisse başı değeri $=12,52 * 0,70$

ROYAL HALI firmasının hisse başı değeri $=8,76 \mathrm{TL}$

Dokuma, Giyim Eşyası Ve Deri Sanayii sektöründe son 10 yıldır faaliyet gösteren firmalara ait mali tablo kalemleri kullanılarak hesaplanan PD/DD oranları aşağıdaki gibidir: 
Tablo 3. Dokuma, Giyim Eşyası Ve Deri Sanayii Sektörü Firmaları İçin PD/DD Oranları

\begin{tabular}{|c|c|c|c|c|c|c|c|c|c|c|}
\hline FÍRMA & 2003 & 2004 & 2005 & 2006 & 2007 & 2008 & 2009 & 2010 & 2011 & 2012 \\
\hline ALTIN & 0,58 & 0,49 & 0,52 & 0,91 & 1,93 & 0,62 & 0,80 & 1,43 & 2,79 & 5,75 \\
\hline ARSAN & 0,65 & 0,43 & 0,53 & 0,40 & 0,51 & 0,29 & 0,82 & 2,07 & 0,71 & 0,87 \\
\hline ATEKS & 0,47 & 0,50 & 0,60 & 0,49 & 0,52 & 0,21 & 0,61 & 0,37 & 0,50 & 0,67 \\
\hline BISAS & 0,44 & 1,25 & 0,79 & 3,00 & 4,75 & 0,87 & - & - & - & 4,78 \\
\hline BOSSA & 0,46 & 0,46 & 0,53 & 0,78 & 0,58 & 0,78 & 0,89 & 0,82 & 0,77 & 0,41 \\
\hline BRMEN & 1,17 & 1,02 & 1,05 & 0,89 & 0,78 & 0,25 & 0,27 & 0,76 & 0,83 & 0,90 \\
\hline DERIM & 2,21 & 2,16 & 2,10 & 1,78 & 1,86 & 0,85 & 1,04 & 1,63 & 1,39 & 0,82 \\
\hline DESA & & 0,94 & 1,04 & 0,73 & 0,89 & 0,32 & 0,60 & 0,90 & 0,79 & 0,57 \\
\hline ESEMS & 1,62 & 1,93 & 4,55 & - & 4,19 & 1,49 & - & 32,11 & 0,31 & 1,05 \\
\hline GEDIZ & 0,69 & 0,87 & 0,91 & 0,89 & 0,36 & 0,15 & 0,52 & 0,27 & 0,72 & 1,77 \\
\hline IDAS & 0,77 & 0,69 & 0,42 & 0,81 & 0,79 & 0,54 & 0,73 & 0,84 & 0,65 & 0,72 \\
\hline KORDS & 0,91 & 0,81 & 1,43 & 1,14 & 1,23 & 0,37 & 0,58 & 0,81 & 0,75 & 0,83 \\
\hline KRTEK & 0,42 & 0,57 & 0,49 & 0,50 & 0,64 & 0,16 & 0,95 & 0,94 & 1,13 & 0,80 \\
\hline LUKSK & 1,18 & 1,05 & 1,53 & 1,40 & 2,21 & 1,23 & 1,73 & 1,00 & 0,72 & 0,55 \\
\hline MEMSA & 0,46 & 1,18 & 1,34 & 0,21 & 0,75 & 0,46 & 0,82 & 0,97 & 0,46 & 0,51 \\
\hline MNDRS & 0,45 & 0,30 & 0,45 & 0,41 & 0,48 & 0,16 & 0,40 & 0,46 & 0,83 & 0,50 \\
\hline SKTAS & 0,35 & 0,42 & 0,50 & 0,39 & 0,69 & 0,26 & 0,38 & 0,72 & 1,19 & 0,63 \\
\hline SNPAM & 1,10 & 1,07 & 1,00 & 0,81 & 2,18 & 0,50 & 1,69 & 2,91 & 2,91 & 2,42 \\
\hline YATAS & 0,77 & 0,51 & 0,79 & 0,66 & 0,57 & 0,24 & 0,66 & 0,87 & 0,65 & 0,69 \\
\hline YUNSA & 0,92 & 0,65 & 0,91 & 0,84 & 0,67 & 0,35 & 0,76 & 1,21 & 1,70 & 2,17 \\
\hline Ortalama & 0,82 & 0,87 & 1,07 & 0,90 & 1,33 & 0,51 & 0,79 & 2,69 & 1,04 & 1,37 \\
\hline \multicolumn{2}{|c|}{ Genel Ortalama } & & & & & 1,14 & & & & \\
\hline
\end{tabular}

Yapılan hesaplamalar sonucunda, yıllar itibariyle ve genel olarak ortalama PD/DD oranlarına ulaşılmıştır. Dokuma, Giyim Eşyası Ve Deri Sanayii sektörü için ortalama PD/DD 1,14 olarak saptanmıştır.

Değerlemesi yapılacak olan ROYAL HALI firmasının 2012 yılı sonu defter değeri 136.752.000 TL, borsada işlem gören hisse senedi sayıs1 ise 60.000.000 adettir. Firmanın hisse başına defter değeri 2,28 TL'dir.

ROYAL HALI firmasının hisse başı değeri = Sektör Ortalama PD/DD * Firmanın Hisse Başı DD

ROYAL HALI firmasının hisse başı değeri $=1,14 * 2,28$

ROYAL HALI firmasının hisse başı değeri $=2,59 \mathrm{TL}$

Dokuma, Giyim Eşyası Ve Deri Sanayii sektöründe son 10 yıldır faaliyet gösteren firmalara ait mali tablo kalemleri kullanılarak hesaplanan F/NA oranları aşağıdaki gibidir: 
Tablo 4. Dokuma, Giyim Eşyası Ve Deri Sanayii Sektörü Firmaları İçin F/NA

Oranları

\begin{tabular}{lrrrrrrrrrr}
\hline FIRMA & $\mathbf{2 0 0 3}$ & $\mathbf{2 0 0 4}$ & $\mathbf{2 0 0 5}$ & $\mathbf{2 0 0 6}$ & $\mathbf{2 0 0 7}$ & $\mathbf{2 0 0 8}$ & $\mathbf{2 0 0 9}$ & $\mathbf{2 0 1 0}$ & $\mathbf{2 0 1 1}$ & $\mathbf{2 0 1 2}$ \\
\hline \hline ALTIN & 4,62 & 3,54 & 3,01 & 14,87 & 13,94 & 23,16 & 4,17 & 4,89 & 20,13 & - \\
ARSAN & 11,79 & 16,79 & 36,48 & 4,16 & 11,42 & - & - & - & 4,38 & 7,71 \\
ATEKS & 6,62 & 4,40 & 9,54 & 7,74 & 39,05 & - & 9,60 & - & 13,22 & 9,32 \\
BISAS & 2,70 & - & - & - & 2,83 & 0,73 & - & - & - & - \\
BOSSA & 3,21 & 2,24 & 3,99 & 3,65 & 3,40 & 4,06 & 10,06 & 12,53 & 3,99 & 4,58 \\
BRMEN & 4,99 & 3,79 & 7,83 & 7,80 & 4,40 & - & 12,81 & 49,34 & - & - \\
DERIM & 28,40 & 5479,37 & 8,90 & 6,06 & 7,83 & 13,71 & 32,36 & 12,93 & 9,21 & 10,31 \\
DESA & - & 5,24 & 9,78 & 10,46 & 7,07 & - & - & 11,96 & 8,21 & 5,31 \\
ESEMS & - & - & - & - & 7,55 & - & - & 0,68 & 0,31 & 8,85 \\
GEDIZ & - & - & - & - & 9,46 & - & - & 2,22 & 11,12 & - \\
IDAS & 3,34 & 3,96 & 25,02 & 20,73 & - & - & 2,50 & - & - & - \\
KORDS & 5,42 & 6,43 & 9,65 & 7,14 & 10,12 & 2,95 & 4,93 & 6,93 & 4,81 & 7,04 \\
KRTEK & 2,61 & 4,63 & - & 5,48 & 5,00 & 16,40 & 11,32 & 15,69 & 10,71 & - \\
LUKSK & 14,50 & 5,95 & 11,64 & 8,48 & 53,55 & - & 21,89 & 36,29 & 10,14 & 6,80 \\
MEMSA & 1,71 & - & - & - & - & - & - & 15,54 & - & - \\
MNDRS & 5,87 & 3,66 & 4,87 & 3,38 & 8,15 & 12,41 & 2,85 & 3,40 & 3,73 & 24,07 \\
SKTAS & 1,58 & 2,12 & 3,77 & 2,67 & 3,30 & 1,45 & 2,13 & 3,28 & 5,58 & - \\
SNPAM & - & 28,63 & 23,30 & - & 19,78 & - & 11,75 & 209,43 & 34,88 & 41,30 \\
YATAS & - & 6,26 & - & 11,37 & 5,08 & - & 10,01 & 10,58 & 5,63 & 14,89 \\
YUNSA & 15,00 & 3,30 & 4,65 & 3,50 & 4,98 & - & 30,51 & 5,41 & 5,19 & 9,09 \\
\hline Ortanca & 4,99 & 4,51 & 9,22 & 7,14 & 7,69 & 8,24 & 10,03 & 11,27 & 6,92 & 8,97 \\
\hline Genel Ortanca & & & & & & $\mathbf{7 , 1 0}$ & & & & \\
\hline \hline & & & & & & & & & &
\end{tabular}

Yapılan hesaplamalar sonucunda, Dokuma, Giyim Eşyası Ve Deri Sanayii sektörü için F/NA oranlara ulaşılmıştır. Tablo 3'te yapılan hesaplamalarda aşırı uç değerler olduğundan ortanca (medyan) yöntemi kullanılmıştır. Sonuçta ilgili sektör için ortalama F/NA 7,10 tespit edilmiştir.

Değerlemesi yapılacak olan ROYAL HALI firmasının 2012 yılı sonu kazanc1 41.940.000 TL, amortisman tutar1 9.395.000 TL, borsada işlem gören hisse senedi sayısı ise 60.000.000 adettir. Firmanın hisse başına nakit akımı 0,86 TL'dir.

ROYAL HALI Firmasının Hisse Başı Değeri = Sektör Ortalama F/NA * Firmanın Hisse Başı NA

ROYAL HALI firmasının hisse başı değeri $=7,10 * 0,86$

ROYAL HALI firmasının hisse başı değeri $=6,11 \mathrm{TL}$ 
Dokuma, Giyim Eşyası Ve Deri Sanayii sektöründe son 10 yıldır faaliyet gösteren firmalara ait mali tablo kalemleri kullanılarak hesaplanan F/S oranları aşağıdaki gibidir:

Tablo 5. Dokuma, Giyim Eşyası Ve Deri Sanayii Sektörü Firmaları İçin F/S Oranları

\begin{tabular}{lrrrrrrrrrr}
\hline FIRMA & $\mathbf{2 0 0 3}$ & $\mathbf{2 0 0 4}$ & $\mathbf{2 0 0 5}$ & $\mathbf{2 0 0 6}$ & $\mathbf{2 0 0 7}$ & $\mathbf{2 0 0 8}$ & $\mathbf{2 0 0 9}$ & $\mathbf{2 0 1 0}$ & $\mathbf{2 0 1 1}$ & $\mathbf{2 0 1 2}$ \\
\hline \hline ALTIN & 0,27 & 0,24 & 0,42 & 0,59 & 1,28 & 0,50 & 0,66 & 1,17 & 1,40 & 2,35 \\
ARSAN & 0,87 & 0,74 & 0,76 & 0,36 & 0,49 & 0,20 & 0,62 & 1,05 & 0,74 & 0,88 \\
ATEKS & 0,35 & 0,36 & 0,44 & 0,36 & 0,39 & 0,16 & 0,42 & 0,48 & 0,57 & 1,11 \\
BISAS & 0,15 & 0,43 & 0,23 & 0,14 & 0,34 & 0,24 & 0,85 & 1,68 & 1,71 & 1,85 \\
BOSSA & 0,42 & 0,44 & 0,64 & 0,78 & 0,53 & 0,84 & 1,03 & 0,74 & 0,75 & 0,47 \\
BRMEN & 0,37 & 0,34 & 0,40 & 0,30 & 0,31 & 0,10 & 0,30 & 0,67 & 0,70 & 1,01 \\
DERIM & 0,62 & 0,59 & 0,53 & 0,36 & 0,40 & 0,16 & 0,19 & 0,25 & 0,20 & 0,16 \\
DESA & - & 0,64 & 0,88 & 0,53 & 0,56 & 0,19 & 0,35 & 0,40 & 0,26 & 0,22 \\
ESEMS & 0,57 & 0,96 & 1,18 & 4,69 & 12,97 & 1,37 & 1,06 & 0,70 & 0,82 & 2,87 \\
GEDIZ & 0,40 & 0,74 & 2,89 & 1,16 & 1,39 & 1,30 & 2,76 & 5,93 & 15,97 & - \\
IDAS & 0,23 & 0,24 & 0,28 & 0,44 & 0,57 & 0,14 & 0,58 & 0,79 & 0,56 & 0,68 \\
KORDS & 0,74 & 0,72 & 1,42 & 0,75 & 0,59 & 0,22 & 0,42 & 0,51 & 0,42 & 0,47 \\
KRTEK & 0,29 & 0,43 & 0,39 & 0,34 & 0,47 & 0,12 & 0,66 & 0,62 & 0,67 & 0,40 \\
LUKSK & 0,92 & 0,99 & 1,51 & 1,19 & 2,06 & 1,45 & 1,70 & 2,89 & 1,43 & 1,46 \\
MEMSA & 0,22 & 0,36 & 0,21 & 0,25 & 3,68 & 0,85 & 6,96 & 19,39 & 1,54 & 3,18 \\
MNDRS & 0,35 & 0,24 & 0,40 & 0,33 & 0,34 & 0,13 & 0,33 & 0,38 & 0,60 & 0,33 \\
SKTAS & 0,30 & 0,39 & 0,56 & 0,44 & 0,65 & 0,23 & 0,37 & 0,62 & 0,90 & 0,62 \\
SNPAM & 1,11 & 1,49 & 1,99 & 1,37 & 4,26 & 0,89 & 7,57 & 9,35 & 9,68 & 8,52 \\
YATAS & 0,30 & 0,18 & 0,33 & 0,25 & 0,21 & 0,09 & 0,24 & 0,31 & 0,26 & 0,27 \\
YUNSA & 0,59 & 0,40 & 0,56 & 0,47 & 0,30 & 0,10 & 0,25 & 0,39 & 0,51 & 0,60 \\
\hline Ortalama & 0,48 & 0,55 & 0,80 & 0,75 & 1,59 & 0,46 & 1,37 & 2,42 & 1,99 & 1,44 \\
\hline Genel Ortalama & & & & & $\mathbf{1 , 1 9}$ & & & & \\
\hline \hline
\end{tabular}

Yapılan hesaplamalar ile ilgili sektörün yıllar itibariyle ve genel olarak ortalama F/S oranlarına ulaşılmıştır. Dokuma, Giyim Eşyası Ve Deri Sanayii sektörü için ortalama F/S 1,19 olarak belirlenmiştir.

Değerlemesi yapılacak olan ROYAL HALI firmasının 2012 yılı sonu satışları tutarı 222.496.000 TL, borsada işlem gören hisse senedi sayısı ise 60.000 .000 adettir. Firmanın hisse başına satışı 3,71 TL'dir.

ROYAL HALI Firmasının Hisse Başı Değeri = Sektör Ortalama F/S * Firmanın Hisse Baş1 S

ROYAL HALI firmasının hisse başı değeri $=1,19 * 3,71$

ROYAL HALI firmasının hisse başı değeri $=4,41 \mathrm{TL}$ 
Dokuma, Giyim Eşyası Ve Deri Sanayii sektöründe son 10 yıldır faaliyet gösteren firmalara ait mali tablo kalemleri kullanılarak hesaplanan FD/FAVÖK oranları aşağıdaki gibidir:

Tablo 6. Dokuma, Giyim Eşyası Ve Deri Sanayii Sektörü Firmaları İçin FD/FAVÖK Oranları

\begin{tabular}{lrrrrrrrrrr}
\hline FİRMA & $\mathbf{2 0 0 3}$ & $\mathbf{2 0 0 4}$ & $\mathbf{2 0 0 5}$ & $\mathbf{2 0 0 6}$ & $\mathbf{2 0 0 7}$ & $\mathbf{2 0 0 8}$ & $\mathbf{2 0 0 9}$ & $\mathbf{2 0 1 0}$ & $\mathbf{2 0 1 1}$ & $\mathbf{2 0 1 2}$ \\
\hline \hline ALTIN & 8,39 & 5,73 & 6,87 & 7,25 & 19,44 & 42,07 & 11,91 & 22,31 & 22,30 & 116,17 \\
ARSAN & 9,69 & 7,30 & $-575,94$ & 6,10 & 244,65 & 25,80 & 21,50 & $-21,89$ & 87,93 & 30,92 \\
ATEKS & 30,76 & 8,34 & $-18,16$ & 10,48 & $-22,64$ & $-16,00$ & 16,96 & $-24,21$ & 15,34 & $-14,95$ \\
BISAS & 2,38 & $-36,49$ & $-2,16$ & $-3,63$ & $-2,76$ & 7,67 & $-982,35$ & 11,63 & 10,75 & 25,21 \\
BOSSA & 18,01 & 2,51 & 6,01 & 4,40 & 4,26 & 7,21 & 19,25 & 18,41 & 7,81 & 17,21 \\
BRMEN & 8,55 & 5,23 & 14,30 & 7,83 & 51,61 & 202,34 & $-83,08$ & $-33,29$ & $-66,69$ & $-25,05$ \\
DERIM & $-13,76$ & $-2895,67$ & 6,96 & 3,77 & 5,79 & 3,15 & 6,61 & 7,19 & 6,58 & 6,92 \\
DESA & 0,43 & 2,92 & 11,25 & 4,09 & $-7,27$ & 20,50 & 32,25 & 69,61 & 4,77 & 17,22 \\
ESEMS & $-6,58$ & $-10,18$ & $-29,98$ & $-17,98$ & 18,60 & $-4,97$ & $-1,86$ & 29,13 & $-53,23$ & $-302,21$ \\
GEDIZ & 4,67 & 2,38 & 17,24 & 58,18 & 58,03 & $-46,34$ & 18,46 & 6,34 & 200,37 & 444,63 \\
IDAS & 3,11 & 3,32 & 21,07 & 11,65 & $-6,76$ & $-4,86$ & $-17,89$ & $-88,64$ & $-6,75$ & $-2,02$ \\
KORDS & 5,74 & 5,29 & 7,35 & 7,56 & 10,88 & 3,15 & 5,17 & 5,54 & 5,32 & 8,73 \\
KRTEK & 5,01 & 5,53 & $-108,44$ & 4,65 & 6,32 & 6,00 & 13,81 & 9,89 & 9,46 & $-56,28$ \\
LUKSK & 6,09 & 3,98 & 16,56 & 8,17 & 86,37 & 13,14 & 18,70 & 38,34 & 12,52 & 11,70 \\
MEMSA & 71,78 & $-9,36$ & $-22,06$ & $-4,41$ & $-22,70$ & 7,44 & $-21,23$ & $-48,48$ & $-13,17$ & $-15,56$ \\
MNDRS & 4,06 & 1,54 & 3,98 & 2,41 & 5,46 & 2,99 & 3,10 & 4,04 & 3,31 & 5,80 \\
SKTAS & 2,86 & 2,44 & 4,87 & 3,96 & 4,06 & 4,49 & 6,92 & 5,86 & 8,38 & $-25,39$ \\
SNPAM & 9,77 & 12,99 & 89,34 & 13,26 & 47,37 & $-12,53$ & 728,64 & 58,23 & 44,48 & 54,12 \\
YATAS & 3,42 & 5,02 & 6,79 & 3,82 & 5,34 & 7,88 & 9,02 & 10,62 & $-35,02$ & 10,12 \\
YUNSA & $-252,53$ & 5,00 & 5,87 & 4,61 & 6,83 & 7,88 & 10,45 & 8,10 & 6,99 & 11,68 \\
\hline Ortanca & 4,84 & 3,65 & 6,40 & 4,63 & 6,05 & 6,61 & 9,73 & 7,65 & 7,40 & 9,42 \\
\hline Genel Ortanca & & & & & $\mathbf{6 , 0 0}$ & & & & \\
\hline \hline
\end{tabular}

Aşırı uç değerler olduğundan ortanca (medyan) yöntemi kullanılarak yapılan hesaplamalar ile sektörün yıllar itibariyle ve genel olarak ortalama FD/FAVÖK oranlarına ulaşılmıştır. Dokuma, Giyim Eşyası Ve Deri Sanayii sektörü için ortalama FD/FAVÖK 6,00 olarak belirlenmiştir.

Değerlemesi yapılacak olan ROYAL HALI firmasının 2012 yılı sonu FAVÖK tutarı 45.357.000 TL, borsada işlem gören hisse senedi sayısı ise 60.000 .000 adettir. Firmanın hisse başına FAVÖK 0,76 TL'dir.

ROYAL HALI Firmasının Hisse Başı Değeri = Sektör Ortalama FD/FAVÖK * Firmanın FAVÖK 
ROYAL HALI firmasının hisse başı değeri $=6,00 * 0,76$

ROYAL HALI firmasının hisse başı değeri $=4,56 \mathrm{TL}$

Piyasa Çarpanlarının Karşılaştırması

03.05.2013 tarihinde halka arz olan ROYAL HALI firmasının 2013 yılı borsa performansı aşağıdaki gibidir:

Tablo 7. Royal Halı Firmasının Borsa Performansı

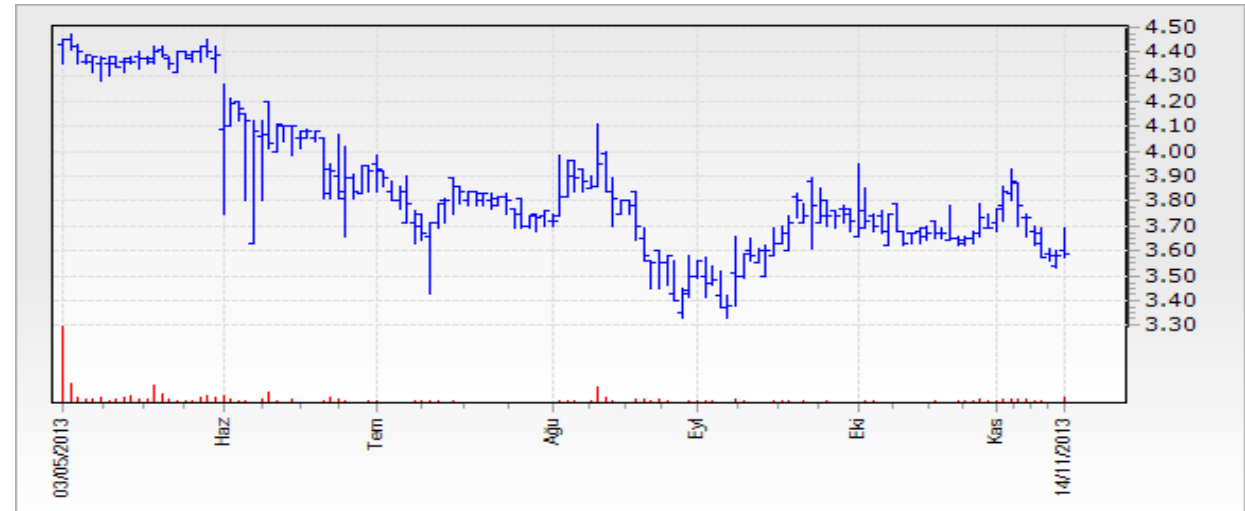

Kaynak:http://www.finnet.com.tr/f2000/Hisse/hisseanaliz.aspx?HISSENO=674\&x=8\&y=8

Tablo 8. Piyasa Çarpanlarının Karşılaştırılması

\begin{tabular}{lccccc}
\hline & F/K & PD/DD & F/NA & F/S & FD/FAVÖK \\
\hline \hline & & & & & \\
Firma Değeri & 8,76 & 2,59 & 6,11 & 4,40 & 4,56 \\
Halka Arz Fiyat Aralı̆̆ı & $4,35-4,75$ & $4,35-4,75$ & $4,35-4,75$ & $4,35-4,75$ & $4,35-4,75$ \\
2013 Y1lı Borsa Performans1 & $3,30-4,50$ & $3,30-4,50$ & $3,30-4,50$ & $3,30-4,50$ & $3,30-4,50$ \\
& & & & & \\
\hline
\end{tabular}

Karşılaştırmalı değerleme yöntemleri kullanılarak hesaplanan ROYAL Halı'nın değeri Fiyat/Satış ve Firma Değeri/FAVÖK oranları, halka arz fiyat aralığında sonuç vermiş, 2013 yılı fiyat hareketlerine yaklaşık değer almıştır. Diğer oranlar halka arz fiyat aralığına girmemiş, firma borsa performans aralığının dışında tahminde bulunmuştur.

\section{SONUÇ}

Tarihi veriler kullanılarak hesaplanan piyasa çarpanlarını esas alan değerleme yöntemleri uygulamada, özellikle Türkiye'de, daha çok kullanılan yöntemlerdir. Türkiye'de hazırlanan değerleme raporları incelendiğinde indirgenmiş nakit akımları analizi yapıldıktan 
sonra piyasa çarpanlarının analizinin yapıldığı görülmektedir. Pek çok faktörün tahmin edilmesini gerektirmediği, hesaplamasının kolay olması bu yöntemi cazip kılmaktadır.

Bu çalışmada değerlemesi yapılacak olan firmanın şirket değeri ile aynı piyasada yer alan diğer firmaların şirket değerlerinin birbirleri için bir anlam ifade ettikleri varsayımından yola çıkılmıştır. BİST Dokuma, Giyim Eşyası Ve Deri Sanayii sektöründe son 10 yıldır faaliyet gösteren firmalara ait mali tablo rakamları kullanılarak hesaplanan çarpanlarla 03.05.2013 tarihinde halka arz olan ROYAL HALI şirketi için firma değeri hesaplanmaya çalışılmıştır.

$\mathrm{F} / \mathrm{K}$ oranı hesaplanırken zarar eden firmalar dikkate alınmamıştır. Bu durum $\mathrm{F} / \mathrm{K}$ oranın en büyük dezavantajıdır. Hesaplanan oranlar arasında uç değerlerin olduğu görülmektedir. F/K oranı ile ROYAL HALI firmasının hisse başı değeri 8,76 TL olarak hesaplanmıştır. Bu fiyat firmanın halka arz fiyat aralığına ve 2013 yılı borsa performans aralığına denk gelmemektedir.

PD/DD oranı ile hesaplanan firma hisse başı değeri 2,59 TL'dir. Bulunan bu fiyat firmanın halka arz fiyat aralığının ve borsa performansının altındadır.

F/NA oranı yöntemi ile yapılan hesaplamada firma hisse başı değeri 6,11 TL olarak tahmin edilmiş fakat bu fiyat halka arz fiyat aralığının ve borsa fiyat aralığının üstündedir.

F/S oranı yönteminin firma hisse başı değeri 4,40 TL olmuştur. F/S oranı BİST Dokuma, Giyim Eşyası Ve Deri Sanayii sektöründeki ROYAL HALI için halka arz fiyat aralığı ve borsa performansı açısından doğru tahminde bulunmuştur.

FD/FAVÖK oranı firma hisse başı değeri tahmininde 4,56 TL fiyat ile halka arz fiyat aralığında, borsa performansına da yakın bir tahminde bulunmuştur.

Piyasa çarpanlarından F/S ve FD/FAVÖK oranları başarılı tahminlerde bulunurken diğer oranlar başarısız olmuştur.

Firma değerlemesinde indirgenmiş nakit akımları ve piyasa çarpanları yöntemlerinin birlikte kullanıldığı görülmektedir. Piyasa çarpanları yöntemi birçok faktörün tahmin edilmesini gerektirmemektedir. Bu yöntemin birçok soruyu cevapsız bırakması en önemli dezavantajıdır. Piyasalar için firmalar ile ilgili geleceğe yönelik beklentilerin önemli olduğu düşünüldüğünde tarihi verileri kullanarak hesaplanan piyasa çarpanlarının değer tespitinde tek başına yeterli olmayacağı söylenebilir. Piyasaların nakit akımlarına göre hareket ettiği düşünüldüğünde, piyasa çarpanları ile tespit edilen firma değerinin indirgenmiş nakit akımları yöntemi ile tespit edilecek firma değeri beraber değerlendirilmesi daha sağlıklı sonuçlar verecektir. 


\section{KAYNAKLAR}

Anthony, R. (1960), The Trouble With Profit Maximization, Harward Business Review.

Asquith, P. (1983), Merger Bids, “Uncertainty and Stockholder Returns”, Journal of Financial Economics, Vol.11, s. 51-84.

Berle, A. A. - Means, G.C. (1932)(Republished:1968): The Modern Corporation and Private Property. Larcourt, Brace \& World Inc., New York

Birgili, E. - Düzer, M. (2010), "Finansal Analizde Kullanılan Oranlar ve Firma Değeri İlişkisi: İMKB'de Bir Uygulama”, Muhasebe ve Finansman Dergisi, Sayı.46, s.74-83

Bradford, C. (1993), Corporate Valuation, John Wiley\&Sons Inc.

Chambers, N. (2009), Firma Değerlemesi, 2. Baskı, Beta Yayınları, İstanbul.

Cheng, C.S.A - McNamara, R. (2000), "The Valuation Accuracy of the Price-Earnings and Price-Book Benchmark Valuation Methods", Review of Quantitative Finance and Accounting, Vol. 15, No. 4, s. 349-370.

Cooke, T. - Omura, T. - Willett, R. (2009), "Consistency, value relevance and sufficiency of book for market values in five Japanese conglomerates over the period 1950 2004”, Journal of Accounting, Finance and Business Studies, Vol.45, No.1, s.88-123.

Çınabal, E. (2008), Muhasebede Değerleme ve Firma Değeri İle İlişkinin Tespiti, Yüksek Lisans Tezi, Gazi Üniversitesi Sosyal Bilimler Enstitüsü İşletme Anabilim Dalı Muhasebe-Finans Bilim Dalı, Ankara.

Ercan, M. - Öztürk, M. - Küçükkaplan, I. - Başcı, E. - Demirgüneş, K. (2006), Firma Değerlemesi ve Banka Uygulaması, Literatür Yayınları, İstanbul.

Hatipoğlu, M. (2011), Firma Değerlemesi ve İMKB'de Enerji Sektöründe Uygulaması, Yüksek Lisans Tezi, Çankırı Karatekin Üniversitesi Sosyal Bilimler Enstitüsü İşletme Anabilim Dalı, Çankırı.

İvgen, H. (2003), Şirket Değerleme, Finnet Yayınları Borsa Dizisi, İstanbul.

Jensen, M. C. - W. H. Meckling. (1976), “Theory of the Firm: Managerial Behavior, Agency Costs and Ownership Structure”, The Journal of Financial Economics 3, s.305-360.

Konuk, H. (2006), Şirket Değerleme Yöntemleri ve Reel Opsiyonlar Yaklaşımı, Yüksek Lisans Tezi, Marmara Üniversitesi Bankacılık Ve Sigortacılık Enstitüsü Sermaye Piyasası Ve Borsa Anabilim Dalı, İstanbul.

Oymak, O. (2009), Firma Değerlemesi ve Bankacılık Uygulaması, Yüksek Lisans Tezi, İstanbul Üniversitesi Sosyal Bilimler Enstitüsü Para, Sermaye Piyasaları ve Finansal Kurumlar Bilim Dalı, İstanbul. 
Park, Y.S. - Jung-Jin,L. (2003), An Empirical Study on The Relevance of Applying Relative Valuation Models to Investment Strategiesin The Japanese Stock Market, Japan and World Economy.

PriceWaterhouseCoopers Türkiye Danışmanlık Hizmetleri. (2006), Şirket Birleşmeleri ve Devralmaları, İnfomag Yayıncılı, İstanbul.

Savsar, A. (2012), Finansal Oranlarla Firma Değeri Arasındaki İlişki ve İstanbul Menkul Kıymetler Borsasında Bir Uygulama, Yüksek Lisans Tezi, Gaziosmanpaşa Üniversitesi Sosyal Bilimler Enstitüsü, Tokat.

Tseng, K.C.(1998), “Low Price, Price-Earnings Ratio, Market Value and Abnormal Stock Returns”, The Financial Review, Vol:23, No:3, s.333-343.

Üreten, A. - Ercan, M.K. (2000), Firma Değerinin Tespiti ve Yönetimi, Gazi Kitabevi, Ankara.

http://www.kap.gov.tr/ (03.11.2013).

http://borsaistanbul.com/ (05.10.2013). 